\title{
FORMATION MECHANISMS FOR THE LARGEST SANDSTONE SINKHOLE IN OHIO
}

\author{
Joshua A. Novello ${ }^{1}$ and Ira D. Sasowsky²
}

\begin{abstract}
Sinkholes formed in sandstone are not common, but are known in locations worldwide. A mechanical origin (i.e. jointing/slumping) for such features is usually invoked and related to the development of crevice caves. Some researchers have inferred a contribution of dissolution processes to the formation of such caves. In northeast Ohio, there are Pennsylvanian age sandstone/conglomerate-capped hills containing small cave systems; sinkholes serve as entrances in some of these. This study investigates the origin of the largest known of these sinkholes-an eight-meter deep, near-vertical pit on the east flank of Little Mountain (Geauga County, Ohio). Structure-From-Motion photogrammetry models the feature for morphometric analysis, using computer and 3-D printed models. Rock and sediment samples were collected to evaluate disaggregation of the bedrock. Adjoining blocks and joints were mapped to place geometric constraints on potential formation mechanisms. The surface opening is a rough, irregular quadrilateral, about $3.8 \mathrm{~m}$ by $6.2 \mathrm{~m}$, and is overhung on three sides. The walls are roughly coincident with joints without distinct fracture surfaces. The floor is sandy and has a few large sandstone boulders apparently emplaced by collapse. At several locations, the walls are spalling off in 3 to 10 centimeter-thick sheets or blocks. Joint-controlled cave passages, some with flowing water, lead into and out of the sinkhole. There is significant variability of induration between samples collected from the host rock. Some samples were poorly indurated, indicating ongoing weathering. The geometry of the sinkhole and adjacent blocks, both in map and vertical perspective, shows that the feature could not have formed solely by simple translation (sliding) of blocks. The overhanging, upper portions do not fit back together if opposite walls of the sinkhole are brought together. Additionally, the major joint to the east of the sinkhole is continuously aligned, which is inconsistent with major motion of the eastern sinkhole wall mass. This sinkhole likely formed and continues to grow through a variety of processes including mechanical joint widening, fluvial erosion, and arenization-cement dissolution, granular disintegration of bedrock and grain transport. Such processes should be considered when evaluating creation of sinkholes in a variety of settings.
\end{abstract}

\section{Introduction}

Sinkholes are common landforms in karst terrains developed on limestone or evaporites, often in association with extensive cave and subterranean drainage systems. Dissolution of soluble bedrock in the presence of undersaturated water is the major cause of sinkhole formation (Gutiérrez et al., 2014). The growth of such features in sandstone is much rarer and has been attributed to the mechanical processes of jointing and slumping, where block displacement produces gaps in the bedrock. Although jointing and slumping are common in northeastern Ohio, several features observed at the sinkhole in this study seem inconsistent with a wholly mechanical genesis via this mechanism. Cement dissolution and granular disintegration of the bedrock may contribute to sinkhole formation; these are explored as possible mechanisms.

Little Mountain, $39 \mathrm{~km}$ northeast of Cleveland in Lake and Geauga Counties, Ohio, is a knob, ranging in elevation from $365 \mathrm{~m}$ to $385 \mathrm{~m}$ above sea level (Fig. 1). To the northwest, a plain grades lakeward to an elevation of $174 \mathrm{~m}$, where it meets Lake Erie (USGS-NGTOC, 2016). Dissected by streams, the region was glaciated by the Wisconsinan, Illinoian and an unknown number of previous ice sheets (Fig. 1 and Ohio Division of Geological Survey, 2005). The knob is composed of Pennsylvanian Sharon Conglomerate, the basal formation of the Pottsville Group, which unconformably overlies the Mississippian Cuyahoga Formation (Stout, 1944). Little Mountain was formerly developed as a resort with hotels, cottages and club houses (Pierson, 1892). The property is currently owned by The Holden Arboretum, as well as some private landowners.

Geomorphology of Little Mountain is similar to "rock cities" described in many localities. Joints, widened into crevices, separate rock blocks resembling streets and buildings in urban settings (Migoń et al., 2017). One such set of crevices in Geauga County is accompanied by a cave system (Fig. 2), Little Mountain Caverns, with a number of sinkholes serving as entrances. The largest of these sinkholes (Figs. 3-A, 3-B, and 3-D) is about $6.2 \mathrm{~m}$ long, $3.8 \mathrm{~m}$ wide, $8 \mathrm{~m}$ deep, tapers to the north, and is the focus of this study. An uneven sinkhole floor is covered in breakdown and sand. Trees at the surface contribute significant leaf litter, and the canopy is visible from the sinkhole floor. The curved walls are covered in thick moss, through which white quartz pebbles and cross stratification remain visible in the bedrock. At the surface, the

${ }^{1}$ Dept. of Geosciences, University of Akron, Akron, Ohio 44325-4101 USA, Jan90@zips.uakron.edu

${ }^{2}$ Dept. of Geosciences \& Center for Environmental Studies, University of Akron, Akron, Ohio 44325-4101 USA, ids@uakron.edu 


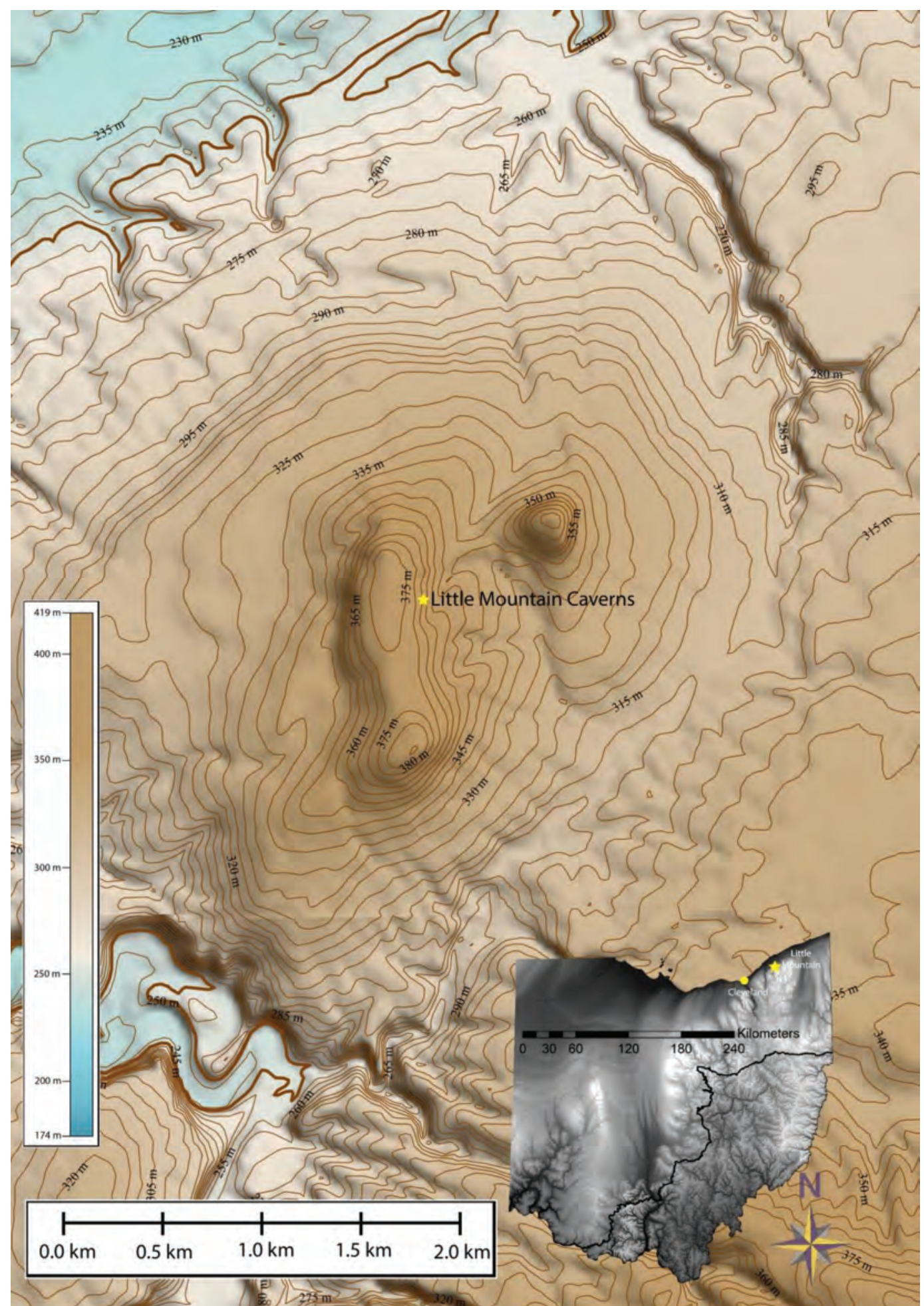

Figure 1. Topographic map of Little Mountain. Base data from Chardon, Chesterland, Mentor and Painesville USGS quadrangles (Ohio Geographically Referenced Information System). Inset map depicting farthest advance of multiple glaciations, modified from Powers et al. (2002) and Ohio Division of Geological Survey (2005).

These fluctuations would have initiated fractures and drained substantial quantities of meltwater through the Sharon Conglomerate on multiple occasions. Pre-Illinoian and Illinoian glaciations may have also contributed to joint formation and propagation as their ice margins advanced or retreated. Cave and sinkhole formation may have initiated as early as pre-Illinoian glaciations.

sinkhole is a rough quadrilateral whose curvilinear edges drop off steeply into the pit. Without a ladder, the sinkhole can be accessed only through a $0.75 \mathrm{~m}$ wide cave passage (Figs. 4-A and 4-B), which intersects its southern end. A cave passage at its northern end terminates against a bedrock wall.

Fyodorova (1998) documented three types of caves in sandstones and conglomerates of northeastern Ohio: fracture caves formed by mechanical processes, true caves, and seepage caves. Dissolution controls the formation of the latter two. Filiano (2014) recognized valley stress relief, exposure to weathering, and dissolution as contributing factors in joint propagation and enlargement, as well as cave formation in this region. Ohio's glacial history may also play a role. The overburden of $1.6 \mathrm{~km}$ thick glaciers (Ohio Division of Geological Survey, 2005) would have depressed the land surface and possibly initiated joints. As the glaciers receded, relieving the overburden, joints and fractures in the Sharon Conglomerate may have propagated due to isostatic rebound. Copious amounts of glacial meltwater would also have passed through the system over a period of years. During the 10,000 years the Wisconsinan ice sheet occupied Ohio, its margin fluctuated significantly (Hansen, 2017). 


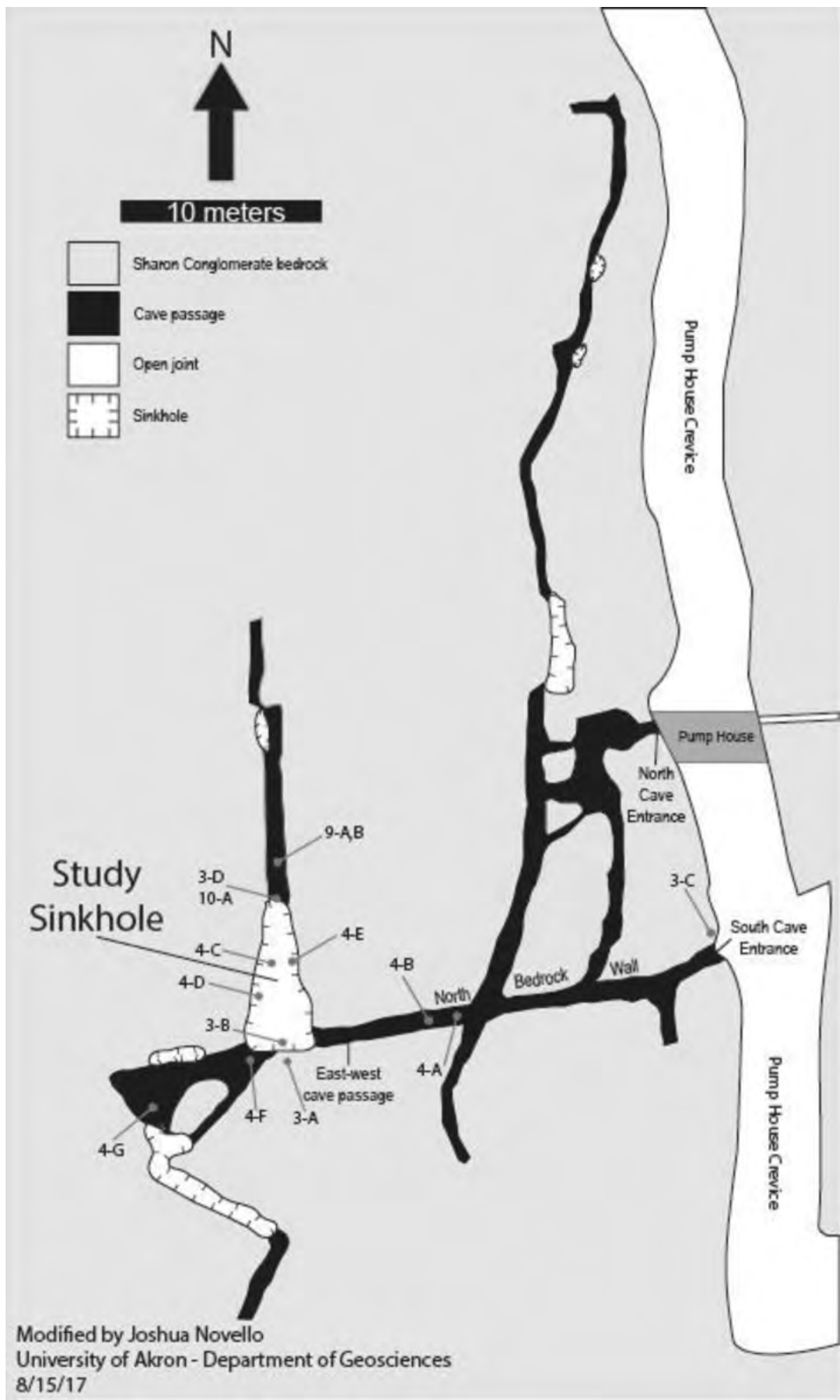

Figure 2. Map of Little Mountain Caverns showing sinkholes, pump house crevice and cave passages. Numbers correspond to figures referenced in text and show the location from which each photo was taken. Cliff face alignment of open joints is approximate. Modified from cave map provided by Ohio Cave Survey, undated.

al Oceanic and Atmospheric Administration, 2016).

Observations of bedrock jointing, fracturing, weathering, and disintegration were recorded. Correlative sedimentary structures and joint patterns were noted and described. Stratigraphic and morphologic features of the sinkhole walls were recorded to determine whether opposing sides fit together. Rock and sediment samples were collected, photographed
Jointing is an important factor in the weathering and erosion of sandstones. Sauro (2014) describes a process whereby arenization is initiated along conjugate joints, and loose sand is then piped or mechanically eroded, resulting in anastomosing pillars. Wray and Sauro (2017) note that arenization-the dissolution of a relatively small fraction of silica cement, followed by fluvial transport of loose sediment-is most effective along existing fractures. Due to the slow reaction rate of silica dissolution, water can remain aggressive for a long time as it travels through strata with high silica content (Martini, 2000). If joints were indeed propagated as glaciers advanced and retreated, subglacial meltwater may have taken advantage of these pathways, initiating arenization and subsequent cave and sinkhole formation processes. The massive volumes of water and amount of time it would have taken to drain make plausible the initiation of karst features via the aforementioned process (Young and Young, 1992). Arenization may continue today with meteoric and seepage water driving dissolution.

The generally-accepted mechanism of sinkhole and cave formation in sandstones of northeastern Ohio is mechanical jointing and slumping. The authors considered that alternative mechanisms could play a significant role in formation as well. This study aimed to investigate the processes that formed what is thought to be the largest sandstone sinkhole in Ohio.

\section{Procedures}

Little Mountain was visited 11 times from September 2016 to March 2017 for data collection. Sinkhole dimensions were mapped using a DistoX survey device (Heeb, 2009). Displacement across a large crevice to the east, in which an abandoned pump house lies, was also measured. Magnetic declination in the study area was $8.66^{\circ} \mathrm{W}$ throughout this study (Nation- 

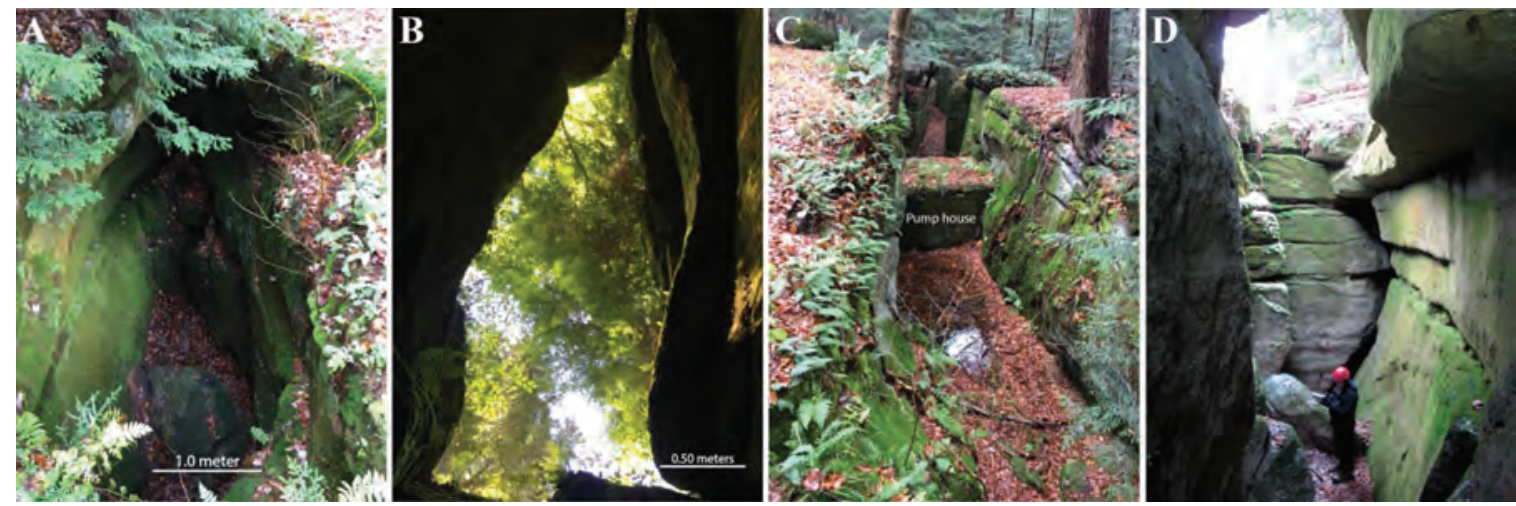

Figure 3. Photographs of sinkhole and surroundings. A) View into the sinkhole from the surface. View is to the north. Depth is 8 meters in the tapered, northern end of the sinkhole. Note crescent-shaped cutout (highlighted in yellow) on eastern edge. Photo courtesy of Noah B. Novello. B) View towards the surface from within the sinkhole. Aperture tapers to the north. C) Pump house crevice, three meters wide. View to the north. Cliff face on the left is roughly parallel to the east wall of the sinkhole. Note relative alignment of crevice faces. Photo courtesy of Noah B. Novello. D) View (southward) from within the sinkhole.
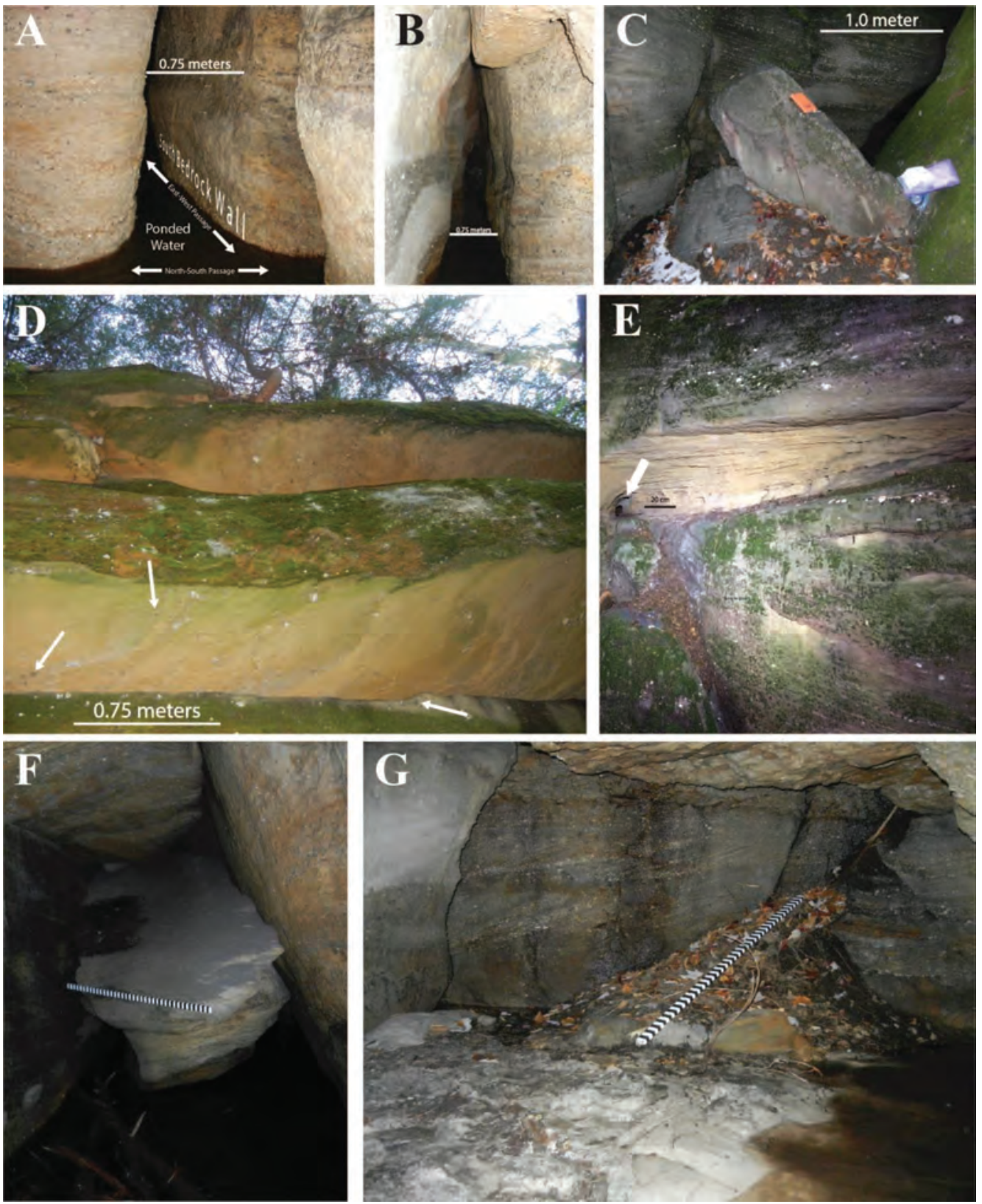

and described using a 10x hand lens for color, weathering, induration, mineral composition, grain size, sorting and rounding. Rock samples were designated as LMRC-\# (Little Mountain Rock Chip) and sediment samples as LMSD-\# (Little Mountain Sediment Deposit).
Figure 4. Photographs of interior of sinkhole and cave passages. A) Cross-cutting north-south and eastwest-trending cave passages. View is to the east. Floor is submerged in water. B) View westward in the eastwest cave passage. Note undercut ceiling and lack of collapse boulder. Passage terminates at sinkhole. C) Sandstone collapse boulders in the center of the sinkhole. View is to the south. D) View upward from interior of sinkhole showing west wall overhanging beds. Moss covered surfaces are vertical in contrast to tan, undercut bedding planes. White arrows indicate manganese-oxide coating present on some pebbles but absent on sand. E) Mid-level conduit in friable sandstone bed, east wall of sinkhole. View is to the northeast. F) Large collapse boulder in a room with significant material missing. G) Accumulation of fine quartz sand in room with low ceiling southwest of sinkhole. A sand cone emanates from the crevice in the upper right. Emery stick is 150 $\mathrm{cm}$ long. View is to the northwest. LMSD-1 collected here. 
Samples were collected in an effort to compare induration between locations in the sinkhole, cave passage and surrounding areas. Location and presence of sediment was noted to determine its origin and transport pathway.

A digital model of the sinkhole was constructed using Structure-From-Motion photogrammetry. A 12.1-megapixel Nikon Coolpix S8100 digital camera was used to take photographs from floor to surface in $360^{\circ}$ with approximately $80 \%$ overlap between consecutive images. A large photoset with significant overlap is required to produce an accurate model (Westoby et al., 2012). Images were imported into Agisoft Photoscan Professional (Agisoft Photoscan Professional, 2016) for photogrammetric processing. A 3-D point cloud was generated by matching key points in each photograph. Imagery was overlain on this 3-D point cloud. The model was then exported as a StereoLithography file (.STL), a format which stores information about the surface geometry of 3-D objects (Chakravorty, 2017). The .STL file was exported to Tinkercad (Autodesk, 2018), a web browser-based, 3-D design tool, where it was further processed and analyzed by the authors. Two printed scale models (Model A, a cast of the sinkhole, and Model B, a mold of the sinkhole) were produced. Both models were used to gain different perspectives of the morphology and geometry of the feature. Model scales are the ratio of length in the model to the length in real space.

Sinkhole volume was determined via a water displacement test using Model A. The model was placed in a thin, plastic bag and submerged in a water-filled beaker. Overflow was poured into two $100 \mathrm{~mL}$ graduated cylinders and volume was recorded. Ten trials were performed and averaged.

Model B was prepared with removal of the upper $\sim 0.5 \mathrm{~m}$ of material in order to simultaneously show the interior morphology and near-surface expression of the sinkhole from map view. Doing so facilitates comparison of the concavity of the model walls and the near-surface expression of the sinkhole.

\section{Results}

\section{Morphology and Modeling}

Depths of the southeastern and northeastern corners of the sinkhole are approximately $8 \mathrm{~m}$ and $6.5 \mathrm{~m}$, respectively. The sinkhole tapers from a width of $3.8 \mathrm{~m}$ at the south end to approximately $0.5 \mathrm{~m}$ at its north end. The long axis of the sinkhole measures $6.2 \mathrm{~m}$ and trends roughly northwest. At the south end, the sinkhole intersects a cave passage trending east-west (Fig. 2). The east wall of the sinkhole and west wall of the pump house crevice are roughly parallel to one another and constitute opposite sides of the same block of rock.

Digital photographs, totaling 857, were processed as described above and were used to generate 3-D PDFs (Fig. 5). Cross-stratification, weathering, vegetation and other features can be easily observed.

Model A (Fig. 6), 1/85 scale, and Model B (Fig. 7), 1/51 scale, were exported to Tinkercad. The volume of Model A, averaged over 10 trials, is $108.5 \mathrm{~cm}^{3}$ (Table 1); hence, the volume of material missing from the sinkhole was determined to be $66.6 \mathrm{~m}^{3}$. Model $\mathrm{B}$ shows the morphology of the bedrock walls of the sinkhole.

\section{Bedrock and Sediment}

Six rock samples were collected and are composed overwhelmingly of detrital quartz. Samples LMRC-3, LMRC-6, and LMRC-7 contained approximately $1 \%$ mica flakes. Samples varied from fine to medium sandstone with quartz-pebble inclusions. Bedrock cement is silica, although hematite is also present. Significant differences of induration exist between samples collected from the host rock, with some disintegrating completely upon collection. Liesegang banding

Table 1. Sinkhole volume derived from water displacement trials using model A, 1/85 scale.

\begin{tabular}{cccc}
\hline Trial & $\begin{array}{c}\text { Volume of Water } \\
\text { Displaced, } \mathbf{~ c m}^{\mathbf{3}}\end{array}$ & $\begin{array}{c}\text { Scaled Sinkhole } \\
\text { Volume, } \mathbf{c m}^{\mathbf{3}}\end{array}$ & $\begin{array}{c}\text { Scaled Sinkhole } \\
\text { Volume, } \mathbf{m}^{\mathbf{3}}\end{array}$ \\
\hline 1 & 108.0 & $66,325,500.0$ & 66.3 \\
2 & 111.5 & $68,474,937.5$ & 68.5 \\
3 & 111.0 & $68,167,875.0$ & 68.2 \\
4 & 108.0 & $66,325,500.0$ & 66.3 \\
5 & 111.5 & $68,474,937.5$ & 68.5 \\
6 & 104.0 & $63,869,000.0$ & 63.9 \\
7 & 104.5 & $64,176,062.5$ & 64.2 \\
8 & 109.0 & $66,939,625.0$ & 66.9 \\
9 & 108.5 & $66,632,562.5$ & 66.6 \\
10 & 109.0 & $66,939,625.0$ & 66.9 \\
& & & \\
Average & 108.5 & $66,632,562.5$ & $66.6 \pm 1.6$ \\
\hline
\end{tabular}



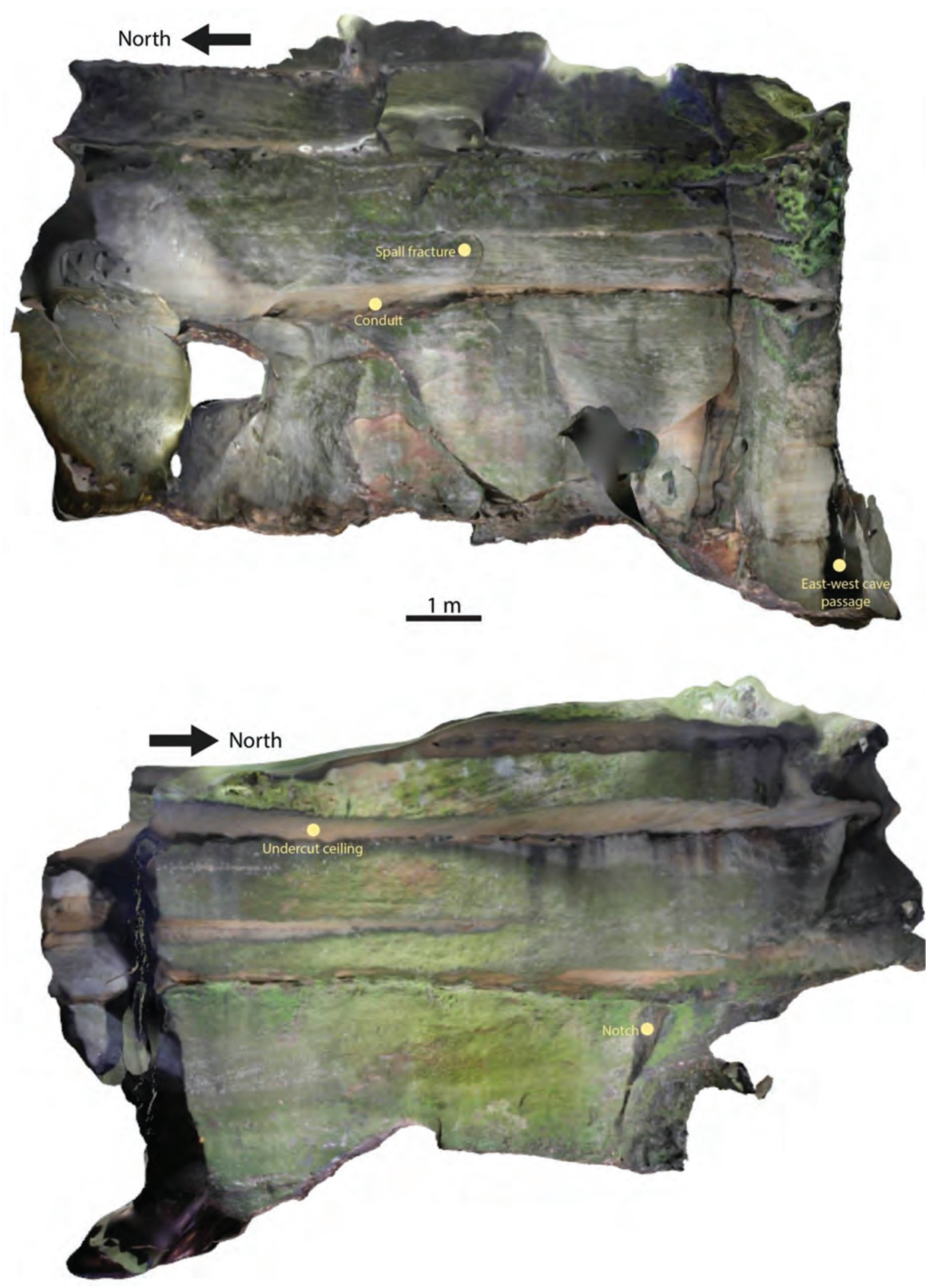

Figure 5. Structure-From-Motion model of the east (top) and west (bottom) walls of the sinkhole.

was observed in samples and throughout cave passages. Aligned, sedimentary structures and crosscutting, perpendicularly-aligned joints were observed in the cave. Sinkhole walls are concave and conglomeratic, especially near the base.

Six sediment samples were collected. All samples taken from within the sinkhole and cave passages were com- 


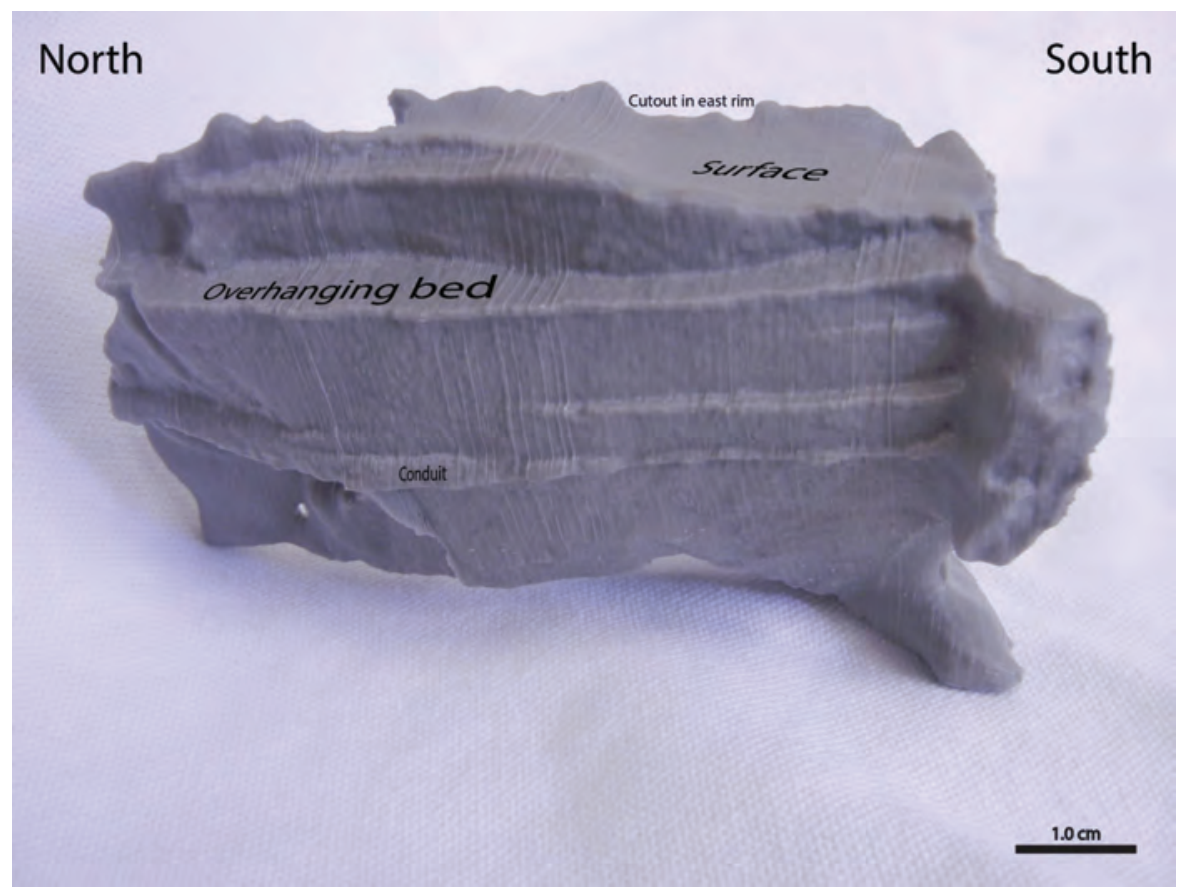

Figure 6. 3-D printed Model A showing the west wall of the sinkhole. Scale is 1:85. Parallel, vertical lines are printing artifacts.

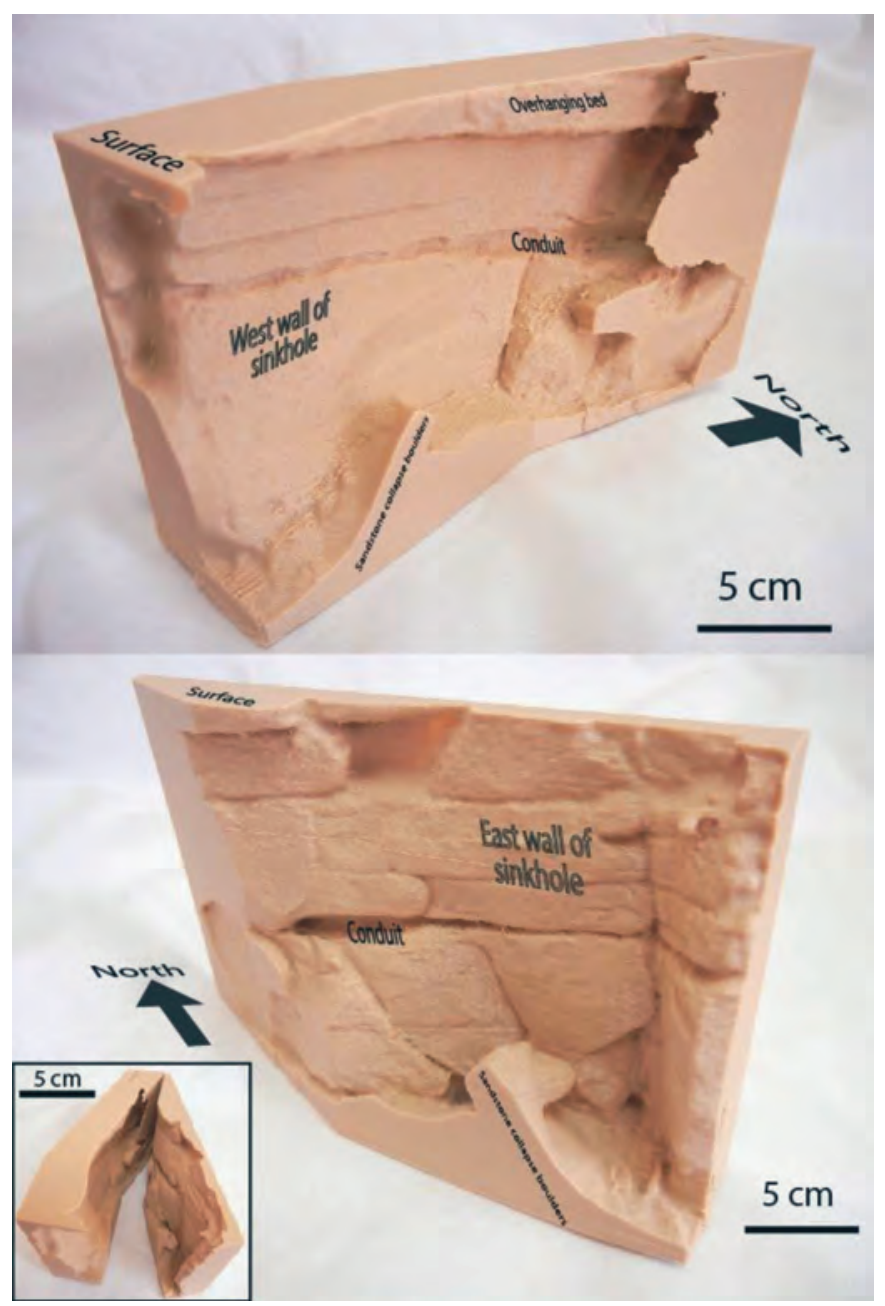

Figure 7. 3-D printed Model B showing walls of the sinkhole. Inset shows model from the surface looking inward. Scale is 1:51. The upper half meter of the sinkhole was excluded from the model to show the surface morphology. posed primarily of quartz sand, with a small fraction of quartz pebbles. Samples collected outside the sinkhole and cave system contained quartz sand and pebbles and varying amounts of organic material. Organic content increased with distance from the sandstone knob.

Several sandstone boulders lie on the sinkhole floor (Fig. 4-C). Along the east rim of the sinkhole, there is a crescent-shaped cutout directly above one of the largest boulders (Fig. 3-A).

Sinkhole walls are overhung on all sides, except the south. The undersides of overhanging beds (Fig. 4-D) are actively weathering. Freshly-weathered surfaces were commonly punctuated by quartz pebbles, covered in manganese oxides. No collapse correlating to the flat underside of these overhanging beds was observed within the sinkhole. Similar overhanging or freshly weathered features were observed on the walls of cave passages, with no associated breakdown (Figs. 4-A and 4-B).

Connecting to the southwest end of the sinkhole, a large room contains a collapse boulder approximately 4 $\mathrm{m}$ long, $1 \mathrm{~m}$ tall, and $2 \mathrm{~m}$ wide (Fig. 4-F). A significant amount of bedrock is missing from this room. Continuing west past this boulder, a low-ceilinged room about $5 \mathrm{~m}$ long, $5 \mathrm{~m}$ wide, and $1.5 \mathrm{~m}$ tall is reached (Fig. 4-G). Bedrock has also been removed from within this room. A sand cone composed of fine quartz sand (LMSD-1) emerges from a crevice in the north wall, fanning out into the room, following the form described by Duszyński et al. (2016).

Several spall fractures were observed within the sinkhole and cave passages (Figs. 5 and 8). A small, poorly cemented spall in the northwest corner of the sinkhole disinte- 


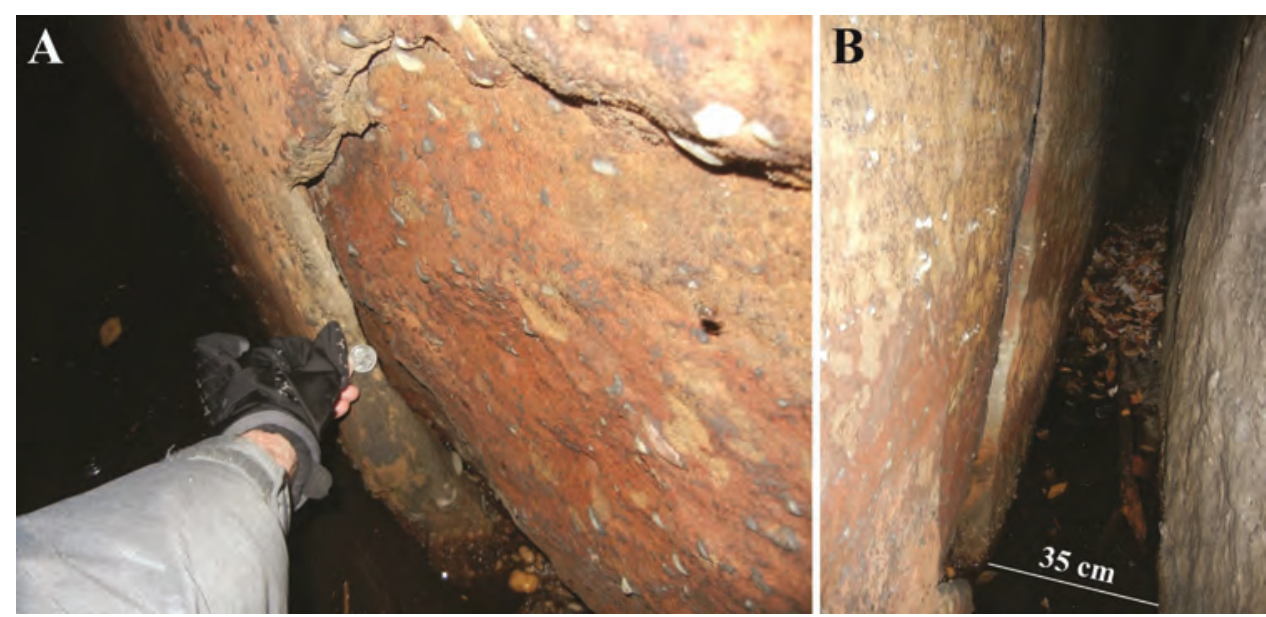

Figure 8. Spall fracture in cave passage north of sinkhole. A) View northeast. B) View south. Note red staining and separation of outer spall from inner wall. LMRC-4 collected at this location.
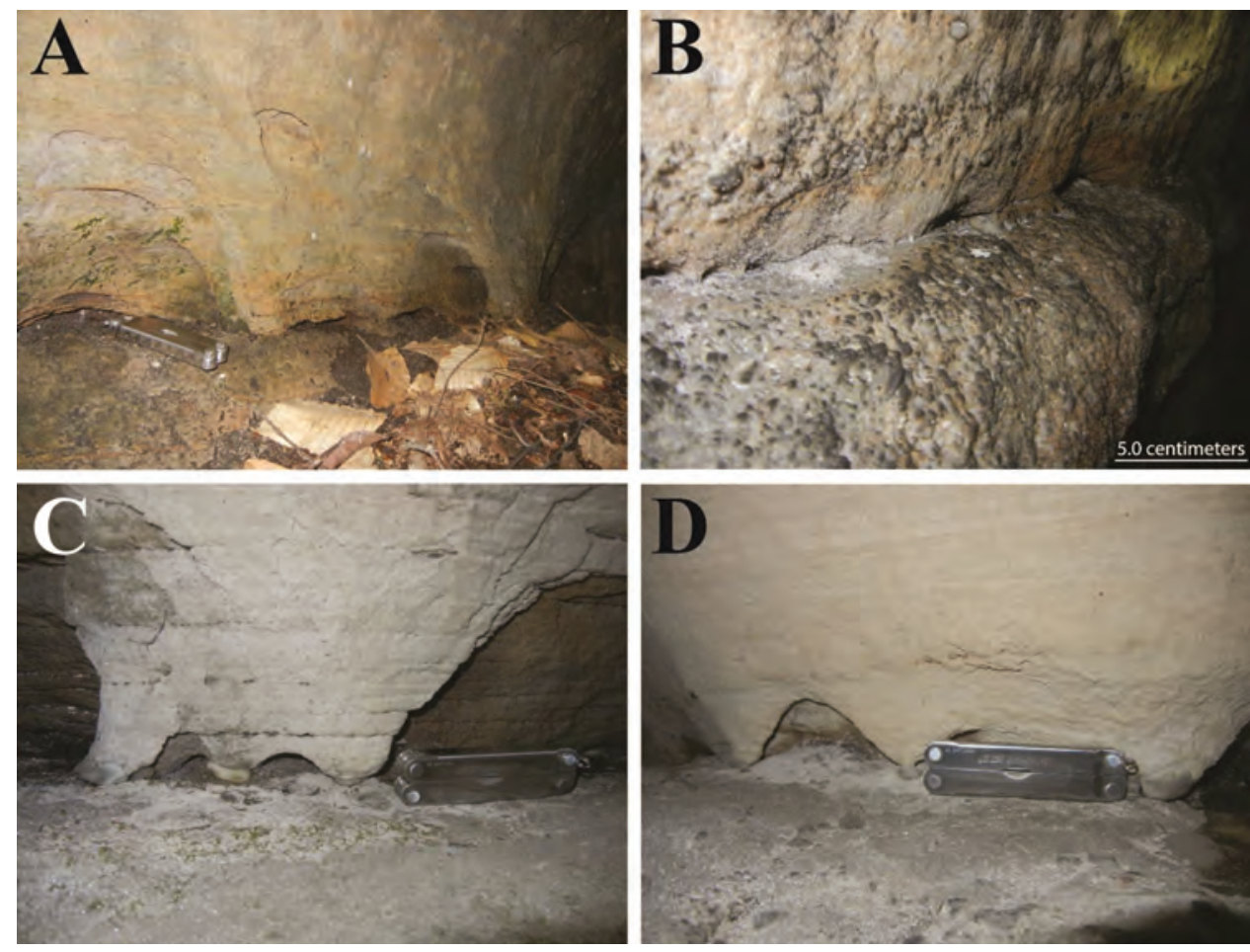

Figure 9. Anastomosing pillars throughout the study area. Note freshly weathered surfaces and loose sand. Multitool (10 cm long) for scale. A) Within the sinkhole. B) Within the east-west cave passage. $C$ and $D$ ) Within a joint to the north of the sinkhole. Note quartz pebble bases.

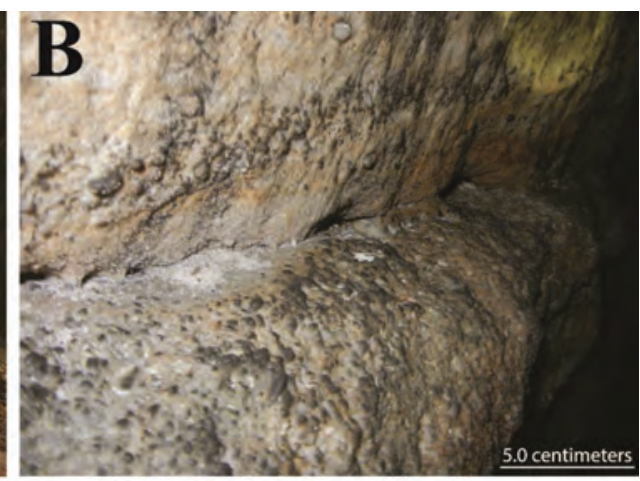

grated completely upon collection. In the north cave passage, a large spall fracture was observed (Fig. 8). The outer wall appears to be parting from the inner, and a small gap has formed between the two. LMRC-4, collected here, is friable but better cemented than the small spall in the sinkhole. The two are separated by roughly four or five meters. Two spall fractures were also observed in the low-ceilinged room southwest of the sinkhole.

Small-scale, anastomosing pillars were observed in a mid-level, friable bed within the sinkhole and in other places throughout Little Mountain (Figs. 9 A-D). These pillars are usually bounded above and below by bedding planes. Frequently, a quartz pebble forms the base of a pillar. Pillars and bounding beds exhibited freshly weathered surfaces. Loose sand was observed in conjunction with these structures.

Loose sand was also observed on the floor of several cave passages, the southern sinkhole entrance and the room southwest of the sinkhole (Fig. 4-F). Sand in the latter was probed to a depth of over $15 \mathrm{~cm}$, indicating a substantial accumulation. Sand at the south end of the sinkhole was estimated to be from 3 to $8 \mathrm{~cm}$ deep.

Sand cones emerging from joints and crevices were observed around the margins of the Little Mountain (Fig. 10). Collected near the apex of one cone, LMSD-5 is composed of $60 \%$ medium, quartz sand and about $40 \%$ organic material. LMSD-4, collected from the base of the same cone, is composed of $5 \%$ medium, quartz sand and $95 \%$ organic material. Significant quantities of sand were also found in soil on the slopes of Little Mountain.

\section{Discussion}

The results and their implications for understanding the processes are summarized in Table 2 with associated figures and references.

\section{Morphology and Modeling-Evidence not explained by translation}

If the sinkhole walls were brought together, the top edges would meet before the interior walls touched, due to their concavity. The walls would not fit like puzzle pieces; a gap would continue to exist between the east and west walls of the sinkhole. The concavity is most readily observed when looking up from within the sinkhole (Fig. 3-B) and along its long axis (Fig. 3-D). Since the gap would not close if the walls were brought together, the sinkhole cannot be the result of simple mechanical separation. 

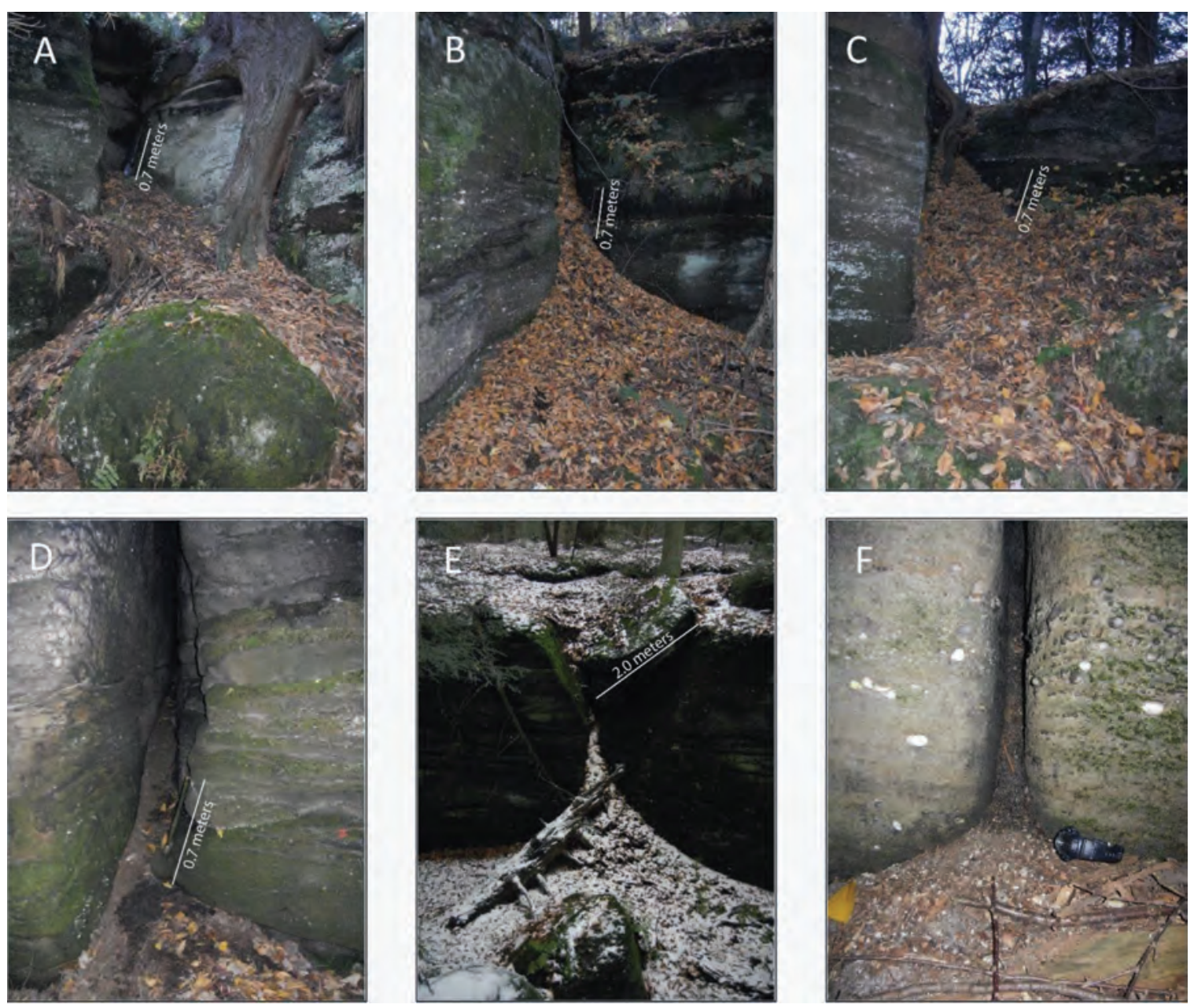

Figure 10. Photographs of sand cones on Little Mountain. A) Southeast of sinkhole in pump house joint (LMSD-4 and LMSD5 collected here). B) South of pump house stream, east of pump house joint. C) Immediately east of southern cave entrance. D) North of pump house. E) North within pump house joint, note collapsed surface block and spreading of cone. F) North of sinkhole, note joint full of sand behind cone. Wristwatch for scale.

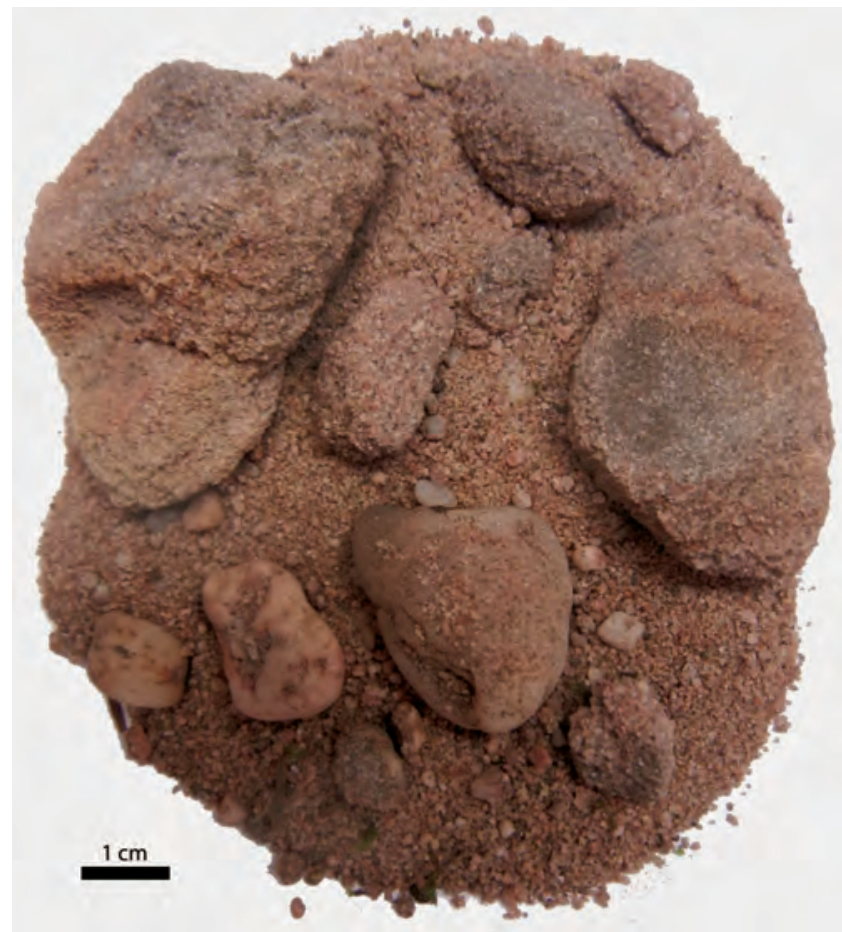

Figure 11. LMRC-1 collected from collapse boulder in sinkhole. Note iron oxide staining.
The east wall of the sinkhole and the west wall of the pump house crevice are roughly parallel to one another (Fig. 2). Bedrock between these walls comprises the north bedrock wall of the southern cave entrance. If jointing and slumping were solely responsible for producing the sinkhole, the north bedrock wall would have advanced downhill farther east than the south block. This block would protrude into the pump house crevice, resulting in a narrower passage. The result would not be the continuously-aligned, evenly-spaced crevice in which the pump house lies (Figs. 2 and 3-C). The southern and northern block crevice faces are relatively aligned. The north crevice face does not reflect the greater eastward advance which would be expected if the sinkhole was the result of block movement.

On opposite walls of the east-west-trending cave passage, planar tabular cross-stratification was observed and appears to have been part of the same dune. Additionally, a north-southtrending cave passage cross cuts the east-west-trending cave passage (Fig. 4-A). This implies alignment of the north and south blocks prior to and after propagation of both joints while the sinkhole may have continued to widen. If the north block had slumped eastward to produce the sinkhole, the northern section of the north-south cave passage would have widened or migrated eastward, relative to the southern section, which is not the case. The north block, therefore, is unlikely to have slumped far enough to the east to produce the sinkhole. 
Table 2. Sinkhole formation mechanisms observed on Little Mountain.

\begin{tabular}{|c|c|c|}
\hline Mechanism & Figure & Source \\
\hline \multicolumn{3}{|l|}{ Arenization/granular disintegration } \\
\hline $\begin{array}{l}\text { Loose sand throughout sinkhole and cave } \\
\text { passages }\end{array}$ & $4-G, 9-A, 9-B$ & Present study \\
\hline Sinkhole concavity & 3-A, 3-B, 3-D, 12 & Present study \\
\hline $\begin{array}{l}\text { Freshly weathered surfaces punctuated by } \\
\text { manganese oxide coated quartz pebbles }\end{array}$ & $\begin{array}{c}\text { 4-A, 4-B, 4-D, 4-E, 5, 8A, 9-A, 9-B, 9-C, } \\
9-\mathrm{D}\end{array}$ & Present study \\
\hline Overhanging beds & $3-B, 3-D, 4-D, 5,6,7$ & Present study \\
\hline Evacuation of bedrock from confined spaces & 3-A, 3-D, 4-F, 4-G & Present study \\
\hline $\begin{array}{c}\text { Anastomosing arches with quartz pebble bases, } \\
\text { loose sand }\end{array}$ & 4-E, 9-A, 9-B, 9-C, 9-D & Fyodorova (1998), present study \\
\hline $\begin{array}{l}\text { Dissolution pits in thin section - evidence of } \\
\text { occurrence in NE Ohio }\end{array}$ & $\cdots$ & Fyodorova (1998) \\
\hline $\begin{array}{l}\text { Continuously aligned walls of pump house } \\
\text { crevice }\end{array}$ & $2,3-C$ & Present study \\
\hline $\begin{array}{l}\text { Aligned joints of the east-west and north-south } \\
\text { trending cave passages }\end{array}$ & $2,4-A$ & Present study \\
\hline \multicolumn{3}{|l|}{$\underline{\text { Underground erosion and fluvial grain transport }}$} \\
\hline Sand Cones & $4-G, 10-A, 10-B, 10-C, 10-D, 10-E, 10-F$ & Duszyński et al. (2016), present study \\
\hline Conduits & $4-E, 5$ & Duszyński et al. (2016), present study \\
\hline \multicolumn{3}{|l|}{ Undercutting and collapse } \\
\hline Boulders within sinkhole & 3-D, 4-C, 12 & Present study \\
\hline
\end{tabular}

Structure-From-Motion photogrammetry was successful in generating accurate 3-D models. Viewing Models $A$ and $B$ as 3-D-printed hand samples provided different perspectives for analysis and feature observation. The actual depth of the south end of the sinkhole was measured to be approximately eight meters, though Mmodel A indicates a depth of $6.3 \mathrm{~m}$, due to absence of the uppermost data. Therefore, the calculated volume of $66.6 \mathrm{~m}^{3}$ is conservative, and the sinkhole is actually greater in volume. This is the largest sandstone sinkhole in Ohio to our knowledge.

\section{Bedrock and Sediments-Evidence for removal of material and undercutting}

Sandstone collapse boulders lie on the floor of the sinkhole (Fig. 4-C). LMRC-1 collected from one of the boulders was friable and disintegrated significantly upon collection, indicating weak cementation (Fig. 11). At the land surface, a crescent-shaped cutout on the eastern rim of the sinkhole may correspond to the rounded edge of the upper boulder (Fig. 3-B). These boulders may have been emplaced via joint propagation, expansion via arenization or fluvial erosion, and subse-

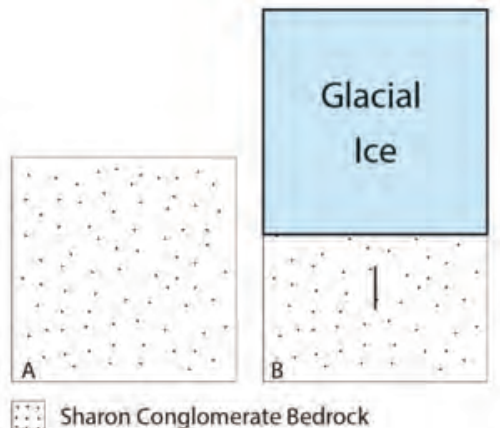

Sharon Conglomerate Bedrock

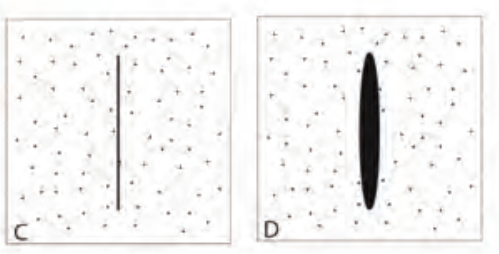

1: Jointed Sharon Conglomerate Bedrock

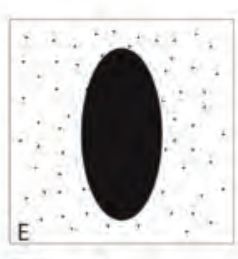

Void

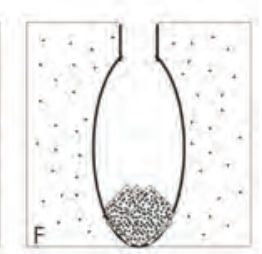

Breakdown

Figure 12. Schematic model showing one possible formation process for the sinkhole. A) Unjointed Sharon Conglomerate. B) Glacial advance exerts tremendous downward force on the bedrock, initiating fractures. C) During and after glacial retreat, glacio-isostatic rebound propagates existing fractures and initiates new fractures. D) Existing joints widen via the arenization process as significant volumes of glacial meltwater, meteoric, and seepage water pass through the conglomerate. E) The void widens significantly, stretching toward the surface as arenization and granular disintegration continue. F) The thin bridge spanning the void collapses into the sinkhole as arenization progresses further toward the surface, resulting in present-day conditions.

quent collapse as the void neared the surface (Fig. 12).

No corresponding breakdown underlies overhanging beds in the sinkhole (Fig. 4-D), suggesting granular disintegration and transport of grains. The tan undersides of overhanging beds appear fresh in 
contrast with gray, weathered, vertical surfaces in the sinkhole, indicating active removal of grains. Similarly, undercutting was observed in cave passages without associated breakdown (Fig. 4-B). In the sinkhole and cave passages, black deposits on the walls, likely manganese oxide, are observed primarily on pebbles in a matrix of uncoated sand. Loose quartz sand, deposited on narrow ledges throughout the cave, may have disaggregated from the bedrock prior to deposition of such oxides (Fig. 9-B), indicating ongoing granular disintegration. Sand on the ledges may also be attributed to incipient anastomosing pillars in the passage. Deposition of this sand by transport from the land surface is not suspected as the deposits are partially recessed into the wall between pillars and also because a true ceiling exists. Sand is also present in the recesses of other pillars (Figs. 9-C and 9-D). Loose sand, observed on the floor of the sinkhole and cave passages, further indicates granular disintegration and subsequent transport from a nearby location.

Two other features in the cave system connected to the sinkhole appear to have formed via bedrock disintegration. The room with the large collapse boulder (Fig. 4-F) and the low-ceilinged room (Fig. 4-G) could not have formed by movement of consolidated bedrock. In both cases, the volumes of bedrock missing are too large to have been removed via the $0.75 \mathrm{~m}$ cave passages as large, indurated masses. Bedrock must have been removed from these confined spaces via granular disintegration and subsequent transport. The low-ceilinged room is now an area of deposition, as a large cone of moderately rounded, well-sorted, $100 \%$ fine quartz sand is present. Similar sand cones have been observed elsewhere on Little Mountain and are discussed below.

Many small-scale, anastomosing pillars were observed in the walls of the sinkhole and surrounding area, usually bounded by bedding planes (Fig. 9). Pillar bases composed of quartz pebbles may be the result of the increased efficacy of arenization on cement between grain boundaries rather than on clasts themselves. Cement dissolution would allow for erosion of individual grains while leaving intact the larger pebble at the base. Freshly weathered surfaces and an abundance of loose sand indicate that these structures represent an active weathering process in the Sharon Conglomerate. If pillars were generated solely by mechanical action of flowing water, the sand grains would have been immediately carried away. Instead, small piles of sand are observed in conjunction with anastomosing pillars. Fyodorova (1998) documented anastomosing pillars in Patterson Farm caves, which are also in the Sharon Conglomerate of Geauga County, Ohio. Other authors have described large-scale, well-developed, anastomosing pillars in Venezuela (Sauro, 2014). Samples collected from the Venezuelan pillars, and examined with a petrographic microscope and SEM, revealed a range of dissolution features indicative of the arenization process, including minor pitting as well as v-shaped dissolution features (Sauro, 2014). Venezuelan pillar formation was attributed to expansion of strata-bound fractures via arenization. Although no petrographic or SEM work was conducted during the current study, Fyodorova (1998) documented pitting, v-shaped notches, and other dissolution features in samples taken from the Sharon Conglomerate and Berea Sandstone in neighboring Cuyahoga, Portage, and Summit counties. While dissolution features are direct evidence of arenization elsewhere in Northeast Ohio, the presence of pillars alone may provide indirect evidence of the arenization process on Little Mountain.

Several sand cones emanate from the cliff faces of Little Mountain in the vicinity of the sinkhole and cave system (Fig. 10). The deposits document processes operating in the area which are also at work in the sinkhole. At the apex of the sand cone in Fig. 10-A, sediment is composed of medium quartz sand and organic debris. Sand fraction decreases significantly near the base of the cone. This may be due to the episodic nature of deposition during periods of high precipitation, while organic material accumulates consistently throughout the year. Sections nearer the apex are generally less exposed to the elements and falling organic debris. Those sections nearer the base are open to the surrounding area, and more frequently receive debris from other sources. The pattern of greater sand fraction near the apex and lower fractions at the base was observed for all sand cones inspected. Cones demonstrate that significant volumes of sediment, matching that which composes the Sharon Conglomerate, have accumulated outside the bounds of the bedrock knob at Little Mountain. A shallow hole was dug downhill to the east, where bedrock is the underlying Cuyahoga Formation. Below the surface, significant quantities of sand, mixed with organic material, indicate that sand from the Sharon Conglomerate is washing downslope. The source of these sheet deposits is likely the sand cones uphill and blocks of Sharon Conglomerate, which have broken from the bedrock cap. Disaggregated bedrock is actively being transmitted outside the knob via joints and crevices.

In the sinkhole, there are a number of possible outlets for disintegrated sand. All cave passageways contain ponded or slowly flowing water. Water originating in a southwest passage flows throughout the cave, exiting through the pump house and draining downhill through a narrow, adjacent joint. Sediment could have been carried into the east-west cave passage during periods of high precipitation. There are also two potential conduits, whose terminations are unknown. The first lies at the contact between the Sharon Conglomerate and the Cuyahoga Formation on the east side of the sinkhole. It presents as a triangular opening, trending northeast. This fracture may intersect an adjacent cave passage, which could drain through the pump house. A second conduit in the mid-level, friable bed may have played an earlier role in sand removal (Fig. 4-E). LMRC-3 disintegrated completely upon collection from this bed. 
Several spall fractures were observed in the sinkhole and cave passages, which also seem to contribute to formation of the sinkhole. Two spalls observed in the room southwest of the sinkhole are larger and analogous to another spall observed in the sinkhole (Fig. 5). The concave morphology of the fractures is consistent with that observed in the sinkhole.

\section{Conclusion}

Numerous lines of evidence (Table 2) point to a complex history for the growth of this sinkhole. If the sinkhole had opened as the result of mechanical movement of the bounding blocks, the western face of the pump house crevice would be displaced eastward. Displacement was not observed in the pump house crevice (Figs. 2 and 3-C).

Simple jointing and slumping are not adequate mechanisms to explain all gaps and voids observed on Little Mountain, and cannot explain formation of the sinkhole. Multiple examples within the sinkhole, cave passages, and surrounding area demonstrate that large volumes of bedrock must have been evacuated from confined spaces as individual sand grains. Variations in induration can be found within as little as $0.5 \mathrm{~m}$. Jointing clearly initiates formation of gaps on Little Mountain. However, other processes must be at work to create the sinkhole and possibly other large openings. Therefore, the hypothesis of jointing and slumping as the sole genetic mechanism is rejected. Arenization is suggested and supported by our data as a plausible mechanism for sinkhole growth (Wray and Sauro, 2017). Silica saturation indices of -1.137 for the spring flowing from the pump house indicate that water flowing at Little Mountain is capable of dissolving silica (Fyodorova, 1998).

This study demonstrates that the largest sandstone sinkhole in Ohio could not have formed solely by mechanical/ translational processes. Continuous alignment of the pump house crevice, as well as those within the cave system, precludes sinkhole genesis via jointing and translation. Multiple glacial advances and retreats, over at least the last 300,000 years, provided ample opportunity for joint propagation, as well as copious volumes of silica-undersaturated water. Joint widening, via arenization, provides a mechanism for loosening of sand while the cave system and crevices act as transport conduits. Enlarged joints could easily result in collapse as they extend toward the surface.

Concave sinkhole wall morphology and anastomosing pillars are analogous to pillars described by Sauro (2014), with meteoric and seepage water likely driving arenization and transport. Conduit flow in non-carbonate rocks at Little Mountain appears to play a significant role in groundwater movement as well as cave and sinkhole development. Although direct evidence of silica dissolution was not evaluated in the present study, several features consistent with arenization have been documented and recognized elsewhere in Northeast Ohio and Venezuela.

A future study could examine individual quartz sand grains for features indicating dissolution of silica cement, such as pitting and formation of $\mathrm{v}$-shaped notches. Additional supporting evidence may be derived from porosity determination within the sinkhole and cave system. Wray and Sauro (2017) suggested that post-arenization porosity of $20 \%$ may result in ready disintegration and transport of quartz grains from a bedrock mass. Evidence from these methods may help determine the degree to which silica dissolution plays a role in sinkhole formation at Little Mountain.

This sinkhole likely formed as flowing water dissolved silica cement in the Sharon Conglomerate and eroded poorly-cemented grains from otherwise confined spaces, resulting in eventual ceiling collapse (Fig. 12). Sand was then transported via the cave system or conduits to cones around the margins of the knob. Grains were further transported downhill via surface runoff and slope transport processes, covering the slopes of Little Mountain in sandy sheet deposits.

\section{Acknowledgements}

We would like to thank Mike Watson and The Holden Arboretum for granting permission and access to conduct this study on Little Mountain. The contributions of the following people in conducting field work were greatly appreciated: Caryn Schuster, Eric, Noah, Roy, and Ronna Novello, RJ McGinnis, Hunter Campbell, Joe Millard and Connor Estes. At the University of Akron, Dr. John Peck, Dr. Shanon Donnelly, Dr. Linda Barrett, Dr. Hazel Barton, Elaine Butcher, Tom Quick and Maria Hawkins provided invaluable assistance and insight. We are grateful to Kathy Sasowsky for reviewing the manuscript and providing thoughtful recommendations. John Harman generously provided the DistoX used for the project. We would also like to thank Dr. Malcom Field, Dr. Benjamin Schwartz, and the three anonymous reviewers who provided valuable recommendations on improvements to this manuscript. Sincere thanks to all who contributed to this project!

\section{References}

Agisoft PhotoScan Professional, 2016, (Version 1.2.6 Software) retrieved from: http://www.agisoft.com/downloads/installer/. Autodesk, 2018, Tinkercad: Tinkercad is a simple, online 3D design and 3D printing app for everyone, https://www.tinkercad.com/. Chakravorty, D., 2017, STL File Format for 3D Printing-Simply Explained: https://all3dp.com/what-is-stl-file-format-extension-3d-printing/ (accessed May 2018). 
Duszyński, F., Migoń, P., and Kasprzak, M., 2016, Underground erosion and sand removal from a sandstone tableland, Stołowe Mountains, SW Poland: Catena, v. 147, p. 1-15. https://doi.org/10.1016/j.catena.2016.06.032.

Filiano, G.L., 2014, Role of joints and rock stresses in the formation of sandstone caves in northeastern Ohio [M.S. thesis]: University of Akron, $200 \mathrm{p}$.

Fyodorova, A.I., 1998, Hydrogeochemical study of cave systems in the Berea sandstone and Sharon sandstone/conglomerate of northeastern Ohio [M.S. thesis]: University of Akron, $121 \mathrm{p}$.

Gutiérrez, F., Parise, M., De Waele, J., Jourde, H., 2014, A review on natural and human-induced geohazards and impacts in karst: Earth-Science Reviews, v. 138, p. 61-88. https://doi.org/10.1016/j.earscirev.2014.08.002.

Hansen, M.C., 2017, The Ice Age in Ohio: Ohio Division of Geological Survey, Educational Leaflet No. 7, Revised Edition.

Heeb, B., 2009, Paperless Cave Surveying, document available at: http://paperless.bheeb.ch/download/DistoX.pdf (accessed October 2016).

Martini, J.E.J., 2000, Dissolution of quartz and silicate minerals. in: Klimchouk, A.B., Ford, D.C., Palmer, A.N., Dreybrodt, W. (eds.), Speleogenesis: Evolution of Karst Aquifers. National Speleological Society, Huntsville, pp. 452-457.

Migoń, P., Duszyński, F., and Goudie, A., 2017, Rock cities and ruiniform relief: Forms-processes-terminology: Earth-Science Reviews, v. 171, p.78-104. https://doi.org/10.1016/j.earscirev.2017.05.012.

National Oceanic and Atmospheric Administration, 2016, Magnetic Field Calculators: https://www.ngdc.noaa.gov/geomag-web/\#declination (accessed November 2016).

Ohio Cave Survey, author and date unknown, Sketch Map of Little Mountain Caverns.

Ohio Division of Geological Survey, 2005, Glacial map of Ohio: Ohio Department of Natural Resources, Division of Geological Survey, page-size map with text, 2 p., scale 1:2,000,000.

Pierson, I.K., 1892, Plan of the Little Mountain Club property, Little Mountain, Geauga County, Ohio.

Powers, D.M., Laine, J.F., and Pavey, R.R., 2002, Shaded elevation map of Ohio: Ohio Division of Geological Survey Map MG-1, 1:500,000 scale.

Sauro, F., 2014, Structural and lithological guidance on speleogenesis in quartz-sandstone: Evidence of the arenization process: Geomorphology, v. 226, p. 106-123. https://doi.org/10.1016/j.geomorph.2014.07.033.

Stout, W., 1944, Sandstones and conglomerates in Ohio: The Ohio Journal of Science, v. 44, no. 2, p. 75-88.

USGS US Topo 7.5-minute map for Mentor, OH 2016: USGS-National Geospatial Technical Operations Center (NGTOC), scale 1:24,000.

Westoby, M.J., Brasington, J., Glasser, N.F., Hambrey, M.J., and Reynolds, J.M., 2012, 'Structure-from-Motion' photogrammetry: A low-cost, effective tool for geoscience applications: Geomorphology, v. 179, p. 300-314. https://doi.org/10.1016/j.geomorph.2012.08.021.

Wray, R. A. L. and Sauro, F., 2017, An updated global review of solutional weathering processes and forms in quartz sandstones and quartzites: Earth-Science Reviews, v. 171, p. 520-557. https://doi.org/10.1016/j.earscirev.2017.06.008.

Young, R. and Young, A., 1992, Sandstone Landforms: Springer-Verlag, Berlin Heidelberg, Germany, 304 p. https://doi.org/10.1007/978-3-64276588-9. 